Vol. 38(2), pp. 217-229, Dec. 2019

ISSN 1821-536X (print)

ISSN 2619-8789 (electronic)
Tanzania Journal of Engineering and Technology

Copyright (C) 2019 College of Engineering and

Technology, University of Dar es Salaam

Full Length Research Paper

\title{
Prediction of Haul Units' Requirements for the Open Pit Mines Operating Towards Closure
}

\author{
Abubakary Salama \\ Department of Chemical and Mining Engineering, College of Engineering and Technology, \\ University of Dar es Salaam, P.O. Box 35131, Tanzania. \\ *Corresponding author: ajasy2000@ gmail.com
}

\begin{abstract}
The determination of haul units is one of the important steps in the equipment selection process. The process should aim at minimizing the operational costs and create an optimal match for the haulage system. When open pit mines operating towards closure, reducing the operational costs results in significant gaining, and the savings can be used to implement some of the closure plans. In this paper, the prediction of haul units for an open pit mine which operates towards the final pit limit was analysed using discrete event simulation and multiple linear regressions. The result shows that the changes in production rate have significantly impact on the number of haul units in operations. The obtained P-value suggests that there is a strong correlation between the haul units' requirement, production rates, and haul distances. This reveals that the prediction of haul units' requirements can be achieved using a developed regression model. It was observed that, the approach of using discrete event simulation and multiple linear regressions is useful in integrating fleet size decision in a multi-period production schedule.
\end{abstract}

Keywords: Discrete event simulation, Haul unit selection, Mine closure, Multiple linear regression analysis, Open pit.

\section{INTRODUCTION}

Mining is the process of excavating economically valuable minerals from the earth using open pit or underground method. When open pit is employed, the final pit limit can be determined based on deposit attributes such as mining cost, grade, tonnage, and processing cost. The pit limit can be defined as the limits of the pit up to which it is economically feasible to mine. When the operations proceed towards final pit limit, the pit size is changing and the production rate starts to vary. During this period, the loading and hauling equipment need to be refined in order to recuperate the production changes. The point at which the haul unit is to be added, downsized, or replaced needs to be identified before the change is made. Determination of the optimal equipment capacity is one of the difficult tasks for the mine planners due to versatility of the equipment capable of performing different operations. Open pit mining operations utilize large scale and expensive equipment. For example, if the mines are implementing shovel and truck systems, trucks usually constitute a large portion in the system and are used for hauling the mined materials. To have sustainable and viable operation, these equipment need to be utilized effectively with minimum operating cost (Topal and Ramazan, 2012). 
Numerous authors have advanced the state of the art in the broad topic of mine planning, optimization, scheduling and equipment selection using various methods such as genetic algorithms, mixed integer programming, and discrete event simulation in solving various mining related problems in both open-pit and underground mining operations (Newman and Kuchta, 2007; Leite and Dimitrakopoulos, 2014; Salama, 2014; Salama et al., 2015). Delurgio et al. (1997), utilized simulation to develop economic equipment selection and sampling plans for integrated circuit manufacturing. They used Monte Carlo simulation model to design and select the optimal solution.

Sturgul (1999) studied the truck-shovel system in a copper mine to simulate if a dispatcher could be used to route the trucks to different shovels to minimize queuing time and improve the operations. Krause and Misungwini (2007) studied a shovel-truck system for loading hauling material in open pit mines using simulation and machine repair models. They concluded that the models produce similar results in fleet size estimations. Brazil and Thomas (2006) designed a connected system of declines, drives, ramps, to minimize capital development and haulage costs over the life time of an open pit mine. The algorithm developed in their analysis can be used by mine planner and designers and test what if scenarios in their mine operations.

Yuriy and Vayenas, (2008) used discrete event simulation to evaluate mine equipment systems combined with a reliability assessment model based on genetic algorithms. They concluded that simulation provides decision for mining companies with regard to their current operating systems in a real-world environment. Mahdavi et al. (2011) developed a simulationbased optimisation for controlling operation allocation and material handling equipment selection. They stated that a validated simulation was more effective in solving the scheduling problems. Choudhury and Chatterjee (2014) addressed the application of a heuristic algorithm without considering the grade constraints for optimising the pit size and then life of mine scheduling for a copper/cobalt deposit in the Central African copper belt.

Most of these developed models detailed describe the fleet selection and optimization during mining operations. To the author's knowledge, no any literature described the equipment process focusing on open pit mines operating towards closure. When mine is in closure plan, the savings can be used to implement some of the closure plans such as covering of reactive tailings dumps, decommissioning of roads, planting of disturbed areas, and on-going monitoring and possible water quality treatment. In this period, the production from time to time is reduced and the closure plans start to be implemented. This implies that loading and hauling equipment need to be optimized to suit the production rate changes. In this paper, the prediction of haul units for an open pit mine, which considers changing the production rates towards the final pit limit was analysed. Therefore, the haul units' requirement for changes of production rate and haul distances for the mine operating towards closure were determined. The analysis was done using discrete event simulation and multiple linear regressions.

\section{Haul Units' Selection}

The haul unit selection and scheduling problems are among the issues that greatly affect the strategic decision of mining operations. Optimum management of haul units plays a key role in having sustainable and economical mining operations towards closure. Many authors agree that transportation costs accounts for almost $50 \%$ of operating costs (Alarie and Gamache, 2002; Nel et al., 2011; Salama, 2014). Minimizing haul units operating costs for the open pit mines operating towards closure results in significant gaining. Fleet management systems such as JigSaw360, Pitram, and Dispatch can be applied to automatically manage the load and haul units', thus, allowing production and fleet adjustment 
(Nel et al., 2011; Chaowasakoo et al., 2017). However, the automated systems require a higher capital investment. For mines operating towards closure a cost reduction is one of the primary focuses. Currently, most of the mines use simple models such as Talpac or equipment manufacturer tools for predicting haul units' requirements. These methods require intense manual input and thus substantially limit the number of haul units analysed which leads to subsequent reduction in detail for the analysis (Nel et al., 2011).

\section{Discrete Event Simulation}

There are several techniques such as computer simulation, artificial neural network, and regressions, which are available and can be applied to predict a combination of trucks and shovels in mining operations (Chanda and Gardiner, 2010). In several open pit and underground hard rock mining, discrete event simulation has been used to examine the productivity of haulage equipment and other mining operations. It is expected that simulation will continue to play an important role in assessing mine designs and plans (Raj et al., 2009).

Discrete event simulation is considered to be a robust tool for optimizing mining operations that consist of uncertainties. Owing to the existence of this uncertainty, simulation is one among the most appropriate tools for equipment selection (Banks et al., 2010). When a system consists of a high degree of uncertainty and random behaviour, the discrete event simulation approach can be considered due to its advantage of more accurate accounting for the real-world uncertainty and diversity of the operations (Salama, 2014).

\section{Multiple Linear Regression Analysis}

Different techniques can be applied to determine the correlation between two or more parameters. Some of these techniques include fuzzy logic, regression analysis, and artificial intelligence like neural network (Cavalieri et al., 2004; Bahri et al., 2015). Multiple regression analysis is one of the appropriate methods in predicting one dependent variable related to more than one independent variables. Multiple regression analysis is a statistical method for finding the values of a dependent variable by its relation to several independent variables. Independent variables comprise a factor that symbolize the impact of dependent variable. This factor is called the coefficient of variation, creating formula based on the data where the values of the variables are known (Cohen et al., 2003).

A number of models for predicting operational parameters have been developed using regression analysis (Cohen et al., 2003; Enayatollahi et al., 2014). A multiple regression model is generally expressed by the relationship between a single outcome variable (Y) and some variables (Xi) as shown in equation (1).

$\mathrm{Y}=\mathrm{a}+b_{1} X_{1}+b_{2} X_{2}+\cdots+b_{n} X_{n} \ldots \ldots \ldots \ldots$

Where Y represents predicted value estimated from $\mathrm{Xi}$, ' $\mathrm{a}$ ' is the intercept, and 'bi' stands for the regression coefficients. The main assumptions of multiple regression analysis are that the relationship between variables is linear and the residues are normally distributed. To obtain the linear relationship, the input (production rate and haul distances) and output (truck requirements) parameters were analysed using Minitab v 17 statistical tool. Before running the regression analysis, the normality distribution assumption was verified using the probability plot of the residues. The probability plot of the residues is normally distributed if most of the values fall onto a straight line in the plot. Also, the normality distribution assumption was accepted or rejected based on the obtained P-value, which refers to the probability of observing a test statistic extreme compared to the one actually observed. To accept or reject the test, the P-values were compared to a 5\% significance level. This means that, if $\mathrm{P}$-value is less than or equal to $5 \%$, the normality test was rejected and if higher was accepted (Cohen et al., 2003). 
The objective of this study was to predict haul units' requirement in order to align with the expected changes on pit geometry and changes in production rate. The analysis was done using discrete event simulation and multiple linear regressions.

\section{METHODS AND MATERIALS}

\section{Description of the Study Area}

The mine used in this study is a single large open pit located in Northern part of Tanzania. The pit size is approximated to be $0.9 \mathrm{~km}$ wide and $1.2 \mathrm{~km}$ long (Figure1). Currently the operations continue at the $1080 \mathrm{~m}, 1040 \mathrm{~m}$, $1070 \mathrm{~m}, 1080 \mathrm{~m}$, and $1140 \mathrm{~m}$ elevations. The final pit limit is expected to be at $930 \mathrm{~m}$ elevation. The life of the mine is currently estimated to be less than two years. The mine is expected to stop production by December 2017, but operation may be extended to February 2018 if delayed. At the time of the study, the mine was still evaluating the possibility of going for the next push back since below $930 \mathrm{~m}$ elevation, there are existing valuable deposit. The mine life will slightly be extended when mine decided to proceed to the next push back, thus the developed prediction model will be useful.

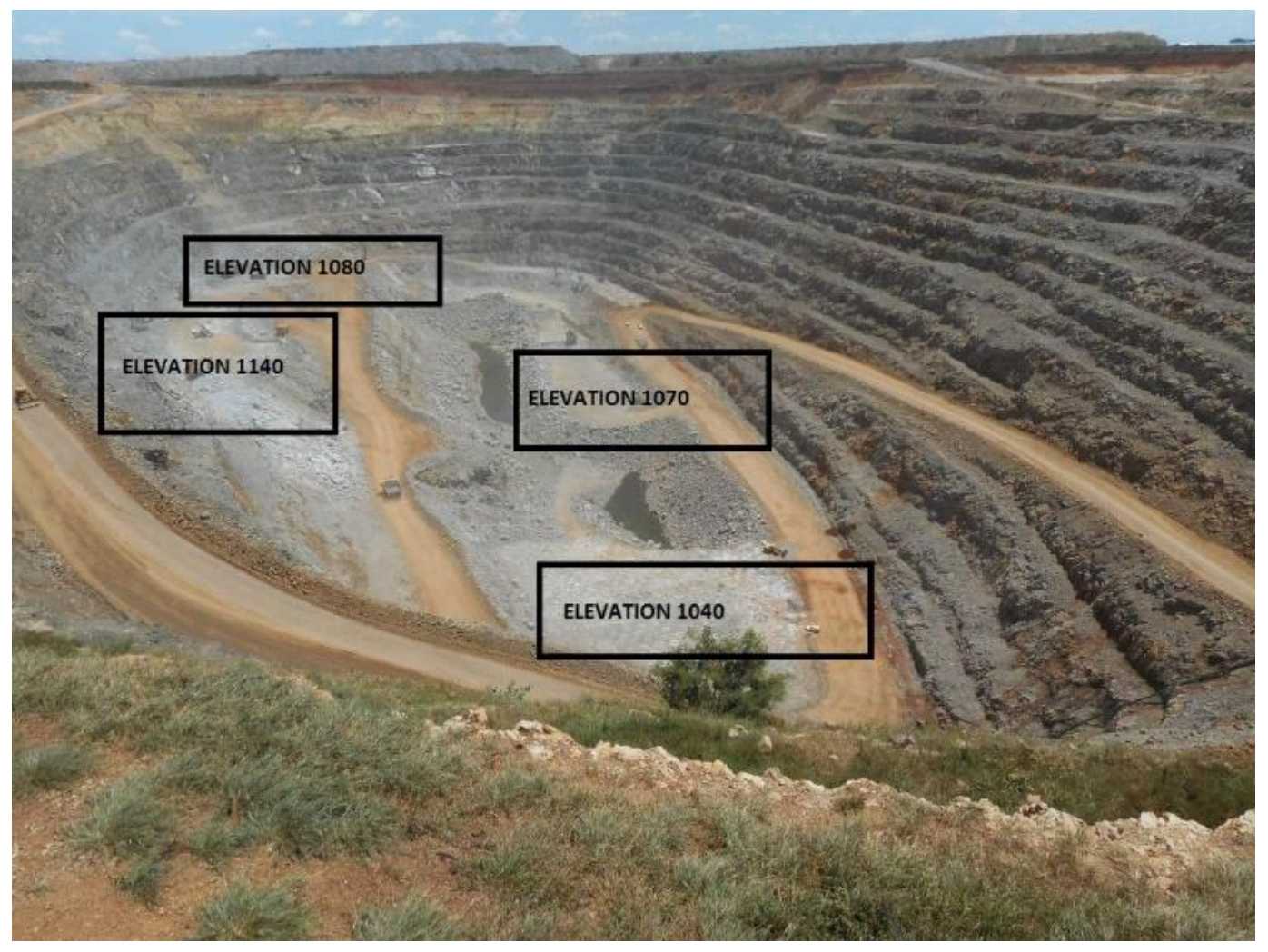

Figure1: The open pit mine used in the analysis

Currently, the mine is operating 17 dump trucks with the rated capacity of 140 tonnes for hauling ore and wastes. Three backhoe excavators each with bucket capacity of $23 \mathrm{~m}^{3}$, and one backhoe shovel with bucket capacity of $13 \mathrm{~m}^{3}$ are used as an auxiliary scheduled for final wall battering and clean ups. These machines load the ore from the pit and transport to the Rompad while the waste materials are transported to the waste dumps.
With these machine configurations, the mine produces around $2.21 \mathrm{Mt}$ of ore and waste per month (as of January 2016). As the operations go further down, the pit geometry becomes narrow and therefore cannot accommodate full fleet when all trucks are in operation. Currently, the mine uses the trial and error methods to predict the truck reductions. 


\section{Discrete Event Simulation Modelling}

Discrete event simulation is continuing to gain attention by mining engineers to predict the performance of mining systems. The model was written in Automod Simulation tool. The tool was chosen because of its ability to capture the dynamic and random nature of the systems. It is also equipped with an interactive debugging feature to trace errors during coding. The simulation model for the prediction of haul units consists of a single pit with several elevations and a single ramp connecting the pit and the destinations which are waste dumps and a Rompad. The final crest elevation at the pit limit is expected to be at $850 \mathrm{~m}$. During operation, four backhoe shovels were used to load various trucks which are controlled by dispatch system, and one backhoe shovel used as an auxiliary scheduled for final wall battering and clean-up. The trucks were allowed to move to the shovels with shorter length of the queue, and equations (2) to (4) were modelled to determine the haul unit productivity (Atkinson, 2008).

$\mathbf{P}_{\text {average }}=\frac{t_{p} * \frac{\mathrm{f}_{\text {fill }}}{\mathrm{f}_{\text {swelling }}} * \mathrm{Q} * \gamma * \frac{\mathrm{v}}{2} * \frac{1000}{60}}{\mathrm{D}_{\max }-\mathrm{D}_{\min }} * \ln$

Where, $P_{\text {average }}$ is the average hourly production rate in $t / h r, \mathrm{D}_{\min }$ is the lowest haul distance covered by a truck, $D_{\max }$ is the highest haul distance, and $\ln$ is the natural logarithm. The input data for simulation was statistically analysed in order to accurately fit various probabilistic distributions. The ramp length in deeper elevations towards final pit limit was estimated using the standard Euclidean length (Brazil and Thomas, 2006):

$L_{(k, l)}=\left|Z_{l}-Z_{k}\right| \sqrt{\left(1+\frac{1}{m^{2}}\right)} \ldots \ldots \ldots \ldots \ldots$

Where $\mathrm{L}_{(\mathrm{k}, \mathrm{l})}$ stands for the length of the ramp link, $\left|Z_{1}-Z_{k}\right|$ represents the difference in vertical elevation between the two end points
$\mathrm{P}_{\mathrm{C}}=\mathrm{Q} * \gamma * \frac{\mathrm{f}_{\text {fill }}}{\mathrm{f}_{\text {swelling }}} \ldots \ldots \ldots \ldots \ldots \ldots$

Cycle time $=\frac{2 \mathrm{D}}{v} * \frac{60}{1000}+t_{\text {fix }} \ldots \ldots \ldots \ldots($

$\mathrm{P}=\frac{\mathrm{P}_{\mathrm{C}}}{\text { Cycle time }} * \mathbf{t}_{p}$

Where $\mathrm{P}_{c}$ is the production rate per cycle, $\mathrm{P}$ is the hourly production rate, $\mathrm{Q}$ represent bucket size in $\mathrm{m}^{3}, \mathrm{f}_{\text {fill }}$ stands for bucket filling factor, yis the ore density in $\mathrm{t} / \mathrm{m}^{3}, \mathrm{D}$ is the one way haul distance in meters, $\mathrm{f}_{\text {swelling }}$ is the swelling factor, $v$ is the average speed over the cycle in kilometres per hour, $\mathrm{t}_{\text {fix }}$ represents fixed cycle time (load, dump, manoeuvre) in minutes, and $t_{p}$ is the operating minutes per hour to account for delays.

When the mine operating towards pit limit, the length of the haul roads increases which results into longer cycle time of the haul units. Due to haul distance variation, the production rate can be calculated using equation (5) (Atkinson, 2008).

$\left[\frac{\frac{2}{v * \frac{1000}{60}} * D_{\max }+t_{f i x}}{\frac{2}{v * \frac{1000}{60}} * D_{\min }+t_{f i x}}\right]$

of the link, $\mathrm{k}$ and 1 are two end points of the link, and $\mathrm{m}$ is the ramp grade, which is $10 \%$.

During simulation all trucks start and end the operation at the parking area which was used as a changing zone. At the end of the shift, all loaded trucks were allowed to move to the changing zone after unloading the material to the designated places. The discrete event simulation was run monthly and the decision to the fleet size reduction was taken during significant production rates reduction. The simulation was first run for the currently situation in the mine which consist of four loading units and seventeen dump trucks working from 6 a.m. until 10 p.m. for the dayshift, and from 10 p.m. until 6 a.m. for the 
night-shift. The output from simulation was applied in establishment of the relationship between future truck requirement, production rate, and haul distance using regression analysis.

\section{Model Validation and Verification}

The verification and validation of the model was done to ensure that the created model is accurate and represents the real system (Muller, 2011). In this study, model verification was done using debugging techniques and running the model under varying conditions. The debugging features were used to make sure that everything was running correctly before resuming execution. Simulation runs were initially conducted with conceptual estimated size of equipment, storage facilities, and haulage systems structures. Initial results allow these parameters to be redefined and radically changed. During modelling, the validation was performed by using a degenerate test, testing internal validity, using an extreme condition test, comparing to historic data, testing face validity, comparing output results with actual system, and through a Turing test (Banks et al., 2010). The validation was done by comparing the output from the discrete event simulation model with the output from the real system.

\section{RESULTS AND DISCUSSION}

\section{Data Collection and Analysis}

Operational data were collected for the period of three months from January to March 2016 in the study area. Random data such as truck loading time, truck speeds, variable digging time, manoeuvring time, and dumping time were analysed using a Minitab statistical tool. The data were fitted in probability distributions that characterizes the uncertainty and randomness of the operation. As seen in Tables 1 and 2, the exponential, normal, and uniform probability distributions were selected to model the loading, dumping times and truck speeds. The empty and loaded truck speeds, and loading time of backhoe excavator followed normal distribution. This is a symmetrical distribution characterized by the mean and standard deviation. The truck dump time was observed to follow uniform distribution. This is because the dump times normally ranges in an open interval and each has equal probability of occurrence. Shovel loading time was characterized as exponential distribution, which is frequently used for operations where nonsymmetrical statistics are observed. This distribution is characterized by a single parameter, which is the mean. In most cases, the shovel loads haul units and sometimes when loaded materials are spilled, bulldozer is required for cleaning.

Table 1: Dump trucks specifications

\begin{tabular}{|l|c|c|c|}
\hline & Distribution & Mean & Standard deviation \\
\hline Speed for empty trucks & Normal & $28 \mathrm{~km} / \mathrm{hr}$ & $3.5 \mathrm{~km} / \mathrm{hr}$ \\
\hline Speed for loaded trucks & Normal & $22 \mathrm{~km} / \mathrm{hr}$ & $4.2 \mathrm{~km} / \mathrm{hr}$ \\
\hline Dump time & Uniform & $14 \pm 64 \mathrm{~seconds}$ & \\
\hline
\end{tabular}

Table 2: Specifications for loading units

\begin{tabular}{|c|c|c|}
\hline Loading Unit & Mean loading time (Seconds) & Standard deviation \\
\hline Shovel (Exponential dist.) & 167.94 & 24.73 \\
\hline Backhoe PC 4000 (Normal distribution) & 171.78 & 26.99 \\
\hline Backhoe PC 2000 (Normal distribution) & 177.14 & 25.52 \\
\hline Backhoe PC 2000 (Normal distribution) & 241.45 & \\
\hline
\end{tabular}


Table 3 shows the haul distances to the Rompad and waste dumps from the current elevation $(1140 \mathrm{~m})$ to the final pit limit $(850$ $\mathrm{m})$. The pit surface at $1226 \mathrm{~m} \mathrm{RL}$ was used to estimate the distances to the waste dumps and Rompad. The distance from the entrance point at the pit surface to the Rompad calculated as $1223 \mathrm{~m}$ while to the waste dump was $800 \mathrm{~m}$. Table shows the monthly production of the ore removed from the pit and transported to the Rompad and waste material dumped to the waste dump. The production rates are based on the mineralization and the pit geometry at a particular elevation. The total amount of ore and waste material to be mined out in year 2016 was 22.4 Mt. Therefore, the truck requirement to match with the production rates was determined. The mine consists of two shifts of 8 hours each and the calculated effective working time of $85 \%$. The availability for both loading and hauling units was $85 \%$. During simulation, all breaks and delays were excluded in order to obtain the effective machine working time.

Table 3: Haul distances from each crest elevations

\begin{tabular}{|c|c|c|c|c|c|}
\hline \multirow[b]{2}{*}{ Year } & \multirow{2}{*}{$\begin{array}{c}\text { Crest } \\
\text { Elevations (m) }\end{array}$} & \multirow{2}{*}{ Depth (m) } & \multirow{2}{*}{$\begin{array}{c}\text { Ramp length } \\
\text { (m) }\end{array}$} & \multicolumn{2}{|c|}{ Haul Distances (m) } \\
\hline & & & & To Rompad & To waste dump \\
\hline \multirow{14}{*}{2016} & 1140 & 86 & 864.29 & 2087.29 & 1664.92 \\
\hline & 1130 & 96 & 964.79 & 2187.79 & 1765.42 \\
\hline & 1120 & 106 & 1065.29 & 2288.29 & 1865.92 \\
\hline & 1110 & 116 & 1165.78 & 2388.78 & 1966.41 \\
\hline & 1100 & 126 & 1266.28 & 2489.28 & 2066.91 \\
\hline & 1090 & 136 & 1366.78 & 2589.78 & 2167.41 \\
\hline & 1080 & 146 & 1467.28 & 2690.28 & 2267.91 \\
\hline & 1070 & 156 & 1567.78 & 2790.78 & 2368.41 \\
\hline & 1060 & 166 & 1668.28 & 2891.28 & 2468.91 \\
\hline & 1050 & 176 & 1768.78 & 2991.78 & 2569.41 \\
\hline & 1040 & 186 & 1869.28 & 3092.28 & 2669.91 \\
\hline & 1030 & 196 & 1969.77 & 3192.77 & 2770.40 \\
\hline & 1020 & 206 & 2070.27 & 3293.27 & 2870.90 \\
\hline & 1010 & 216 & 2170.77 & 3393.77 & 2971.40 \\
\hline \multirow{13}{*}{2017} & 1000 & 226 & 2271.27 & 3494.27 & 3071.90 \\
\hline & 990 & 236 & 2371.77 & 3594.77 & 3172.40 \\
\hline & 980 & 246 & 2472.27 & 3695.27 & 3272.90 \\
\hline & 970 & 256 & 2572.77 & 3795.77 & 3373.40 \\
\hline & 960 & 266 & 2673.27 & 3896.27 & 3473.90 \\
\hline & 950 & 276 & 2773.76 & 3996.76 & 3574.39 \\
\hline & 940 & 286 & 2874.26 & 4097.26 & 3674.89 \\
\hline & 930 & 296 & 2974.76 & 4197.76 & 3775.39 \\
\hline & 920 & 306 & 3075.26 & 4298.26 & 3875.89 \\
\hline & 910 & 316 & 3175.76 & 4398.76 & 3976.39 \\
\hline & 900 & 326 & 3276.26 & 4499.26 & 4076.89 \\
\hline & 890 & 336 & 3376.76 & 4599.76 & 4177.39 \\
\hline & 880 & 346 & 3477.26 & 4700.26 & 4277.89 \\
\hline \multirow{3}{*}{2018} & 870 & 356 & 3577.75 & 4800.75 & 4378.38 \\
\hline & 860 & 366 & 3678.25 & 4901.25 & 4478.88 \\
\hline & 850 & 376 & 3778.75 & 5001.75 & 4579.38 \\
\hline
\end{tabular}


Table 4: Planned production during mine closure

\begin{tabular}{|l|c|c|c|}
\hline \multicolumn{4}{|c|}{ Monthly planned production (2016) } \\
\hline Months & Waste material (Tonnes) & Ore (Tonnes) & Total material (Tonnes) \\
\hline January & $1,937,773$ & 272,228 & $2,210,000$ \\
\hline February & $1,893,893$ & 216,107 & $2,110,000$ \\
\hline March & $2,004,600$ & 235,401 & $2,240,000$ \\
\hline April & $1,800,475$ & 389,525 & $2,190,000$ \\
\hline May & $1,812,778$ & 427,222 & $2,240,000$ \\
\hline June & $1,645,689$ & 584,311 & $2,230,000$ \\
\hline July & $1,577,619$ & 652,381 & $2,230,000$ \\
\hline August & $1,391,541$ & 518,459 & $1,910,000$ \\
\hline September & 1,126645 & 753,355 & $1,880,000$ \\
\hline October & $1,193,345$ & 746,655 & $1,940,000$ \\
\hline November & 720,639 & 509,361 & $1,230,000$ \\
\hline December & 755,136 & 514,864 & $1,270,000$ \\
\hline
\end{tabular}

\section{Model Simulation}

The simulation was done first for the current situation in the mine (January 2016), which involves four loading units and seventeen dump trucks which used to move 2,210,000 tonnes of ore and waste. The simulation results were presented in Figure 2. During this time, the operation was at $1140 \mathrm{~m}$ crest elevation.

Figure 2 shows that for the current situation, 17 trucks are required to move 2,205,580 tonnes of material to Rompad and waste dumps. The simulation results were observed to be very close to the real situation in the mine with the variance of $0.2 \%$. After the first simulation, the model was adjusted and the analysis was conducted at various production rates and haul distances. It was observed that the production rate variations have significant impact on the number of trucks in operations. For example, for September 2016, the trucks requirement to move $1,883,760$ tonnes of waste and ore material was almost half of the trucks required to move 2,205,580 tonnes for January. This was because of the idle time and time wasted by the haul units while waiting for each other at the loading points and haul ways. It was further observed that the production rate was not constantly reduced from January to December, instead the production was slightly increased and then reduced between these months.

The simulation was then conducted to see the relationship between the truck's requirements and variable in haul distance when four backhoe shovels are digging striping and post striping materials and transported to both Rompad and waste dumps (Figure 3). The haul distances for deeper elevations were estimated based on the standard Euclidean length presented in equation (5), for different values of crest elevations. As expected, it shows that the number of trucks reduced with an increase of haul distances. In principle, when haul distance increases, the truck cycle times also increases which results in achieving low production. In this case, as the operations proceeds towards final pit limit, the haul distances increased and the production rate was decreased, meaning that fewer trucks will be required. The decrease in number of trucks leads to a reduction in average loading unit's utilisation due to a higher idle time when waiting for the trucks. Number of haul units was determined based on the matching factor. These results show that with the knowledge of the load and haulage cycles, production rate, and the variable haul distances, it is possible to predict the number of trucks required to meet 
the planned production when machine specifications, operational parameters and geometrical characteristics of the pit are known.

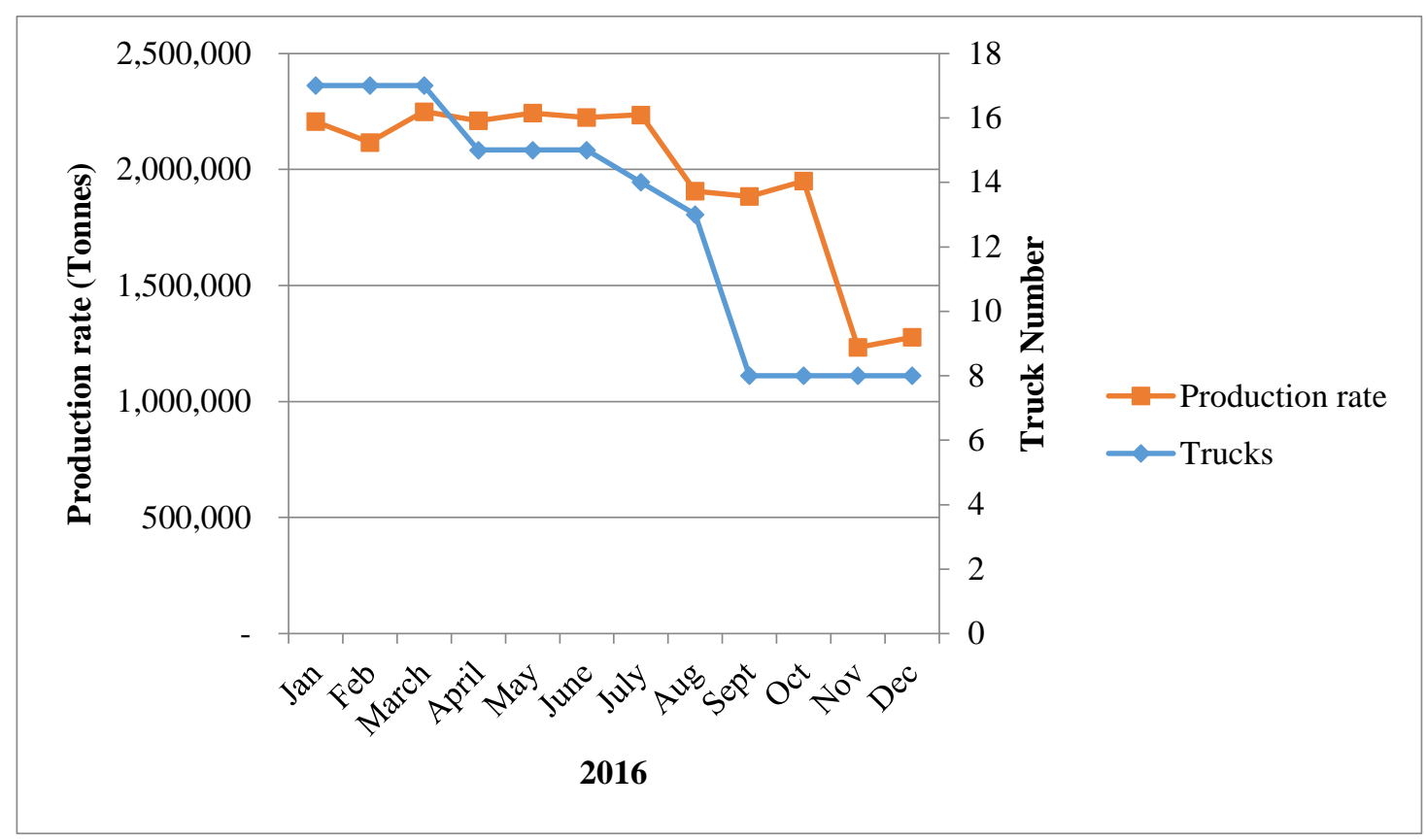

Figure 2: Fleet optimization for year 2016

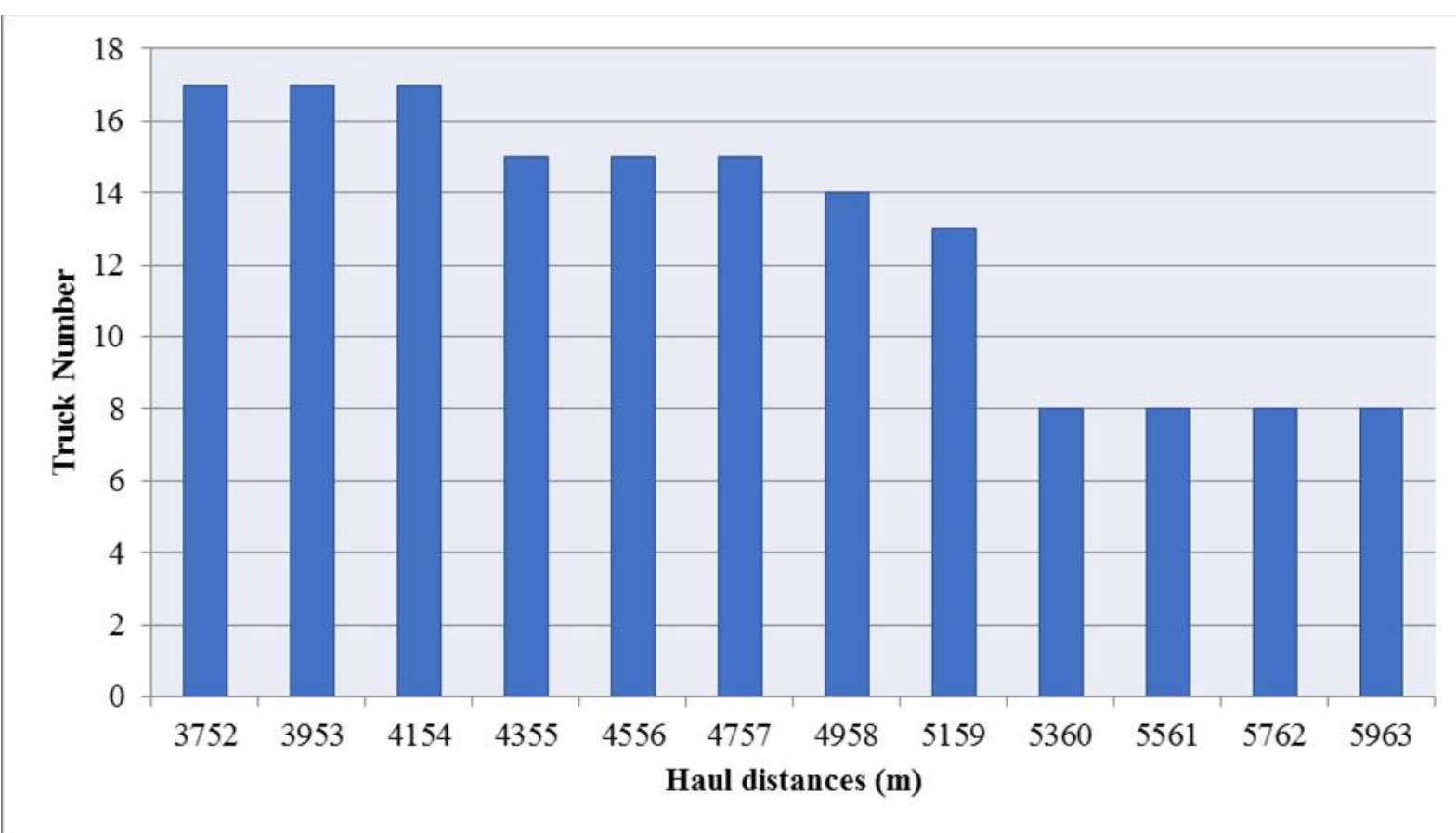

Figure 3: Trucks requirement versus haul distances to Rompad and waste dumps

Table 5 presents the number of trucks required in relation to the simulated production rates for the twelve months of 2016. The number of loading units in operation was obtained based on the match factor. Matching of loading and haul units is one among the important consideration criteria in selecting the number of the loading and haulage system equipment. When matching factor is below 1 , it indicates that a system is under trucked, if it is above 1, 
it shows that the system is over trucked and when it is exactly 1 means that the expression is a theoretical match. It can be observed that, for closely similar production rates, the number of trucks can be maintained. If there is significant change of production rates, the numbers of trucks can from time to time being adjusted. These results reveal that the impact of over or under trucked fleets can have a significant influence on the productivity of mining operations towards the closure. With these results, it is possible to estimate the number of haul equipment at a variable production rates for deeper elevations using multiple linear regression. To obtain the linear relationship, the input (production rate and haul distances) and output (truck requirements) parameters were analysed using Minitab v 17 statistical tool (Table 6).

\section{Table 5: Number of trucks requirements}

\begin{tabular}{|c|c|c|c|c|}
\hline Months & $\begin{array}{c}\text { Total material } \\
\text { (Tonnes) }\end{array}$ & Trucks & $\begin{array}{c}\text { Haul Distance } \\
(\mathbf{m})\end{array}$ & $\begin{array}{c}\text { Number of } \\
\text { loading units }\end{array}$ \\
\hline January & $2,210,000$ & 17 & 3752 & 4 \\
\hline February & $2,110,000$ & 17 & 3953 & 4 \\
\hline March & $2,240,000$ & 17 & 4154 & 4 \\
\hline April & $2,190,000$ & 15 & 4355 & 4 \\
\hline May & $2,240,000$ & 15 & 4556 & 4 \\
\hline June & $2,230,000$ & 15 & 4757 & 4 \\
\hline July & $2,230,000$ & 14 & 4958 & 4 \\
\hline August & $1,910,000$ & 13 & 5159 & 3 \\
\hline September & $1,880,000$ & 8 & 5360 & 3 \\
\hline October & $1,940,000$ & 8 & 5561 & 3 \\
\hline November & $1,230,000$ & 8 & 5762 & 2 \\
\hline December & $1,270,000$ & 8 & 5963 & 2 \\
\hline
\end{tabular}

Before running the regression analysis, the first thing was to check if the normality distribution assumption is valid using the probability plot of the residues. The probability plot of the residues are normally distributed if most of the values fall onto a straight line in the plot. Also the normality distribution assumption is accepted or rejected based on the obtained $\mathrm{P}$ value, which refers to the probability of observing a test statistic extreme compared to the one actually observed. To accept or reject the test, the P-values were compared to a $5 \%$ significance level. This means that, if P-value is less than or equal to $5 \%$, the normality test is rejected and if higher is accepted (Cohen et al., 2003). The analysis of normality test reveals that the hypothesis is accepted. This is because the P-value obtained (0.056) was higher than the level of significance.
After the normality test, the multiple regression analysis was then perfomed and the evaluation was based on P-value. If the P-value is $\leq 0.05$ for the variables, then it will be perceived as statistically significant otherwise it will be rejected. The equation (7) with $\mathrm{R}^{2}$ of 0.889 as the multiple linear regression for truck requirement prediction has been obtained. This means that there is a strong correlation between the analyzed parameters as the $88.9 \%$ of the variation in the predicted parameter is explained by the regression model. In this model, none of the parameters were removed as all of them provided less error and high value of $R^{2}$.

As seen in Table 7, the P-values for the production rate and haul distance variables $(<$ 
0.05) suggests that there is a strong positive correlation between the predicted and the measured parameters. The large constant value is due to low number of observations. The obtained equation was further analyzed by comparingthe predicted and the measured parameters. It was observed that the predicted truck requirement computed by linear regression is close to the measured parameters (production rate and haul distance) with the value of $\mathrm{R}^{2}$ obtained as 0.89 .

$\mathrm{TR}=31.55+0.000001 *(\mathrm{PR})-0.004402(\mathrm{HD})$.

Where TR is the truck requirement, PR stands for production rate reduction, HD represents variation of haul distances. On the Minitab v 17 statistical software, analysis of the effects of each individual measured parameter on the predicted parameter was carried out. The results were evaluated based on P-value ( $\leq$ $0.05)$. The results show that, when production rate and haul distances were separately measured against truck requirements, the Pvalues were observed to be $\leq 0.05$. This suggests that there is a correlation between predicted parameter and each of independent parameters. It was revealed that when a mine is operating towards closure, optimum number of haul units becomes a critical issue for reducing operational problems and costs in the material handling system. It was observed that prediction of truck requirements is correlated with the production rates and haul distances in the situation where pit geometry decreases towards mine closure. It could be observed that the proposed model provides solutions related to the estimation of the number of haul units. The multiple linear regression model presented under the circumstances described in this paper, can be updated and applied in the preliminary and detail evaluation of any mining operations considering adjusting fleet size when heading towards closure.

Table 6: Multiple regression analysis input data

\begin{tabular}{|l|c|c|c|}
\hline Months & Trucks & $\begin{array}{c}\text { Total } \\
\text { material } \\
\text { (Tonnes) }\end{array}$ & $\begin{array}{c}\text { Haul } \\
\text { Distance (m) }\end{array}$ \\
\hline January & 17 & $2,110,000$ & 3752 \\
\hline February & 17 & $2,110,000$ & 3953 \\
\hline March & 17 & $2,240,000$ & 4154 \\
\hline April & 15 & $2,190,000$ & 4355 \\
\hline May & 15 & $2,240,000$ & 4556 \\
\hline June & 15 & $2,230,000$ & 4757 \\
\hline July & 14 & $2,230,000$ & 4958 \\
\hline August & 13 & $1,910,000$ & 5159 \\
\hline September & 8 & $1,880,000$ & 5360 \\
\hline October & 8 & $1,940,000$ & 5561 \\
\hline November & 8 & $1,230,000$ & 5762 \\
\hline December & 8 & $1,270,000$ & 5963 \\
\hline
\end{tabular}


Table 7: Multiple Regression analysis

\begin{tabular}{|c|c|c|c|c|}
\hline Term & Coef & SE Coef & P-Value & VIF \\
\hline Constant & 31.55 & 8.03 & 0.003 & \\
\hline Production rate & 0.000001 & 0.000002 & 0.0485 & 2.73 \\
\hline Haul distance & -0.004402 & 0.000963 & 0.001 & 2.73 \\
\hline
\end{tabular}

\section{CONCLUSIONS}

The prediction of haul units for an open pit mine which considers changing the production rates towards mine closure was analysed using discrete event simulation and multiple linear regressions. The P-values obtained from the regression analysis reveal that there is a strong correlation between the truck requirement, production rate, and haul distances. This shows that it is possible to estimate the number of haul units for a given production rates and haul distances. The change in production rates and haul distances has significant impact on the number of haul units. For the year 2016, the trucks required were progressively reduced from 17 to 15 in April, to 14 in July, to 13 in August, and to 8 in the period of September to December. In year 2017, the haul units' requirements were accurately predicted using the developed model. It can be concluded that discrete event simulation and multiple linear regression is a useful approach in integrating fleet size decision in a multi-period production schedule for other mines operating towards closure.

\section{REFERENCES}

Atkinson T. (2008). Selection and sizing of excavating equipment, in SME Mining Engineering Handbook, H.L Hartman, $2^{\text {nd }}$ ed., Littleton CO SME, 1311-1333.

Alarie S. and Gamache M. (2002). Overview of solution strategies used in truck dispatching systems for open pit mines. International Journal of Surface Mining, Reclamation and Environment, $\quad 16(1)$ : 59-76. https://doi.org/10.1076/ijsm.16.1.59.3408.

Banks J., Carson J.S., Nelson B.L. and Nicol D.M. (2010). Discrete Event System simulation, Pearson Education, New Jersey.
Bahri N.A, Ebrahimi F.M. and Reza S.G. (2015). A fuzzy logic model to predict the out-of-seam dilution in longwall mining. International Journal of Mining Science and Technology, 25(1): 91-98. https://doi.org/10.1016/j.ijmst.2014.12.002.

Brazil M. and Thomas D.A. (2006). Network optimization for the design of underground mines. Networks, 49(1): 40-50. https://doi.org/10.1002/net.20140.

Cavalieri S., Maccarrone P. and Pinto R. (2004). Parametric vs. neural network models for the estimation of production costs: a case study in the automotive industry. International Journal of Production Economic, $\quad 91(2)$ : 165-177. https://doi.org/10.1016/j.ijpe.2003.08.005

Cohen J., Cohen P., West S.G. and Aiken L.S. (2003). Applied multiple regression/correlation analysis for the behavioural sciences. Lawrence Erlbaum Associates, Routledge.

Chanda E. and Gardiner S. (2010). A comparative study of truck cycle time prediction methods in open pit mining. Engineering, Construction and Architectural Management, 17(5): 446-460. https://doi.org/10.1108/09699981011074556

Choudhury S. and Chatterjee S. (2014). Pit optimization and life of mine scheduling for a tenement in the Central African Copperbelt. International Journal of Surface Mining, Reclamation and Environment, 28(3): 200-213. https://doi.org/10.1080/17480930.2013.8118 $\underline{02}$

Chaowasakoo P, Seppälä H, Koivo H. and Zhou Q. (2017). Digitalization of mine operations: Scenarios to benefit in real-time truck dispatching. International Journal of Mining Science and Technology, 27(2): 2229-236.

https://doi.org/10.1016/j.ijmst.2017.01.007 
Delurgio Sr S.A., Foster Jr, S.T. and Dickerson G. (1997). Utilizing simulation to develop economic equipment selection and sampling plans for integrated circuit manufacturing. International Journal of production research, 35(1): 137-155. https://doi.org/10.1080/002075497196028

Enayatollahi I., Bazzazi A.A. and Asadi A. (2014). Comparison between neural networks and multiple regression analysis to predict rock fragmentation in open pit mines. Rock mechanics and rock Engineering, 47(2): 799-807. https://doi.org/10.1007/s00603-013-0415-6

Krause A. and Misungwini C. (2007). Modelling open pit shovel-truck systems using the machine repair model. Journal of Southern African Institute of Mining and Metallurgy, 107(8): 469-476.

Leite A. and Dimitrakopoulos R. (2014). Stochastic optimization of mine production scheduling with uncertain ore/metal/waste supply. International Journal of Mining Science and Technology, 24(6): 755-62. https://doi.org/10.1016/j.ijmst.2014.10.004

Mahdavi I., Shirazi B. and Sahebjamnia N. (2011). Development of a simulation-based optimisation for controlling operation allocation and material handling equipment selection in FMS. International Journal of Production Research, 49(23): 6981-7005. https://doi.org/10.1080/00207543.2010.5348 $\underline{26}$

Muller D. (2011). Automod-modeling complex manufacturing, distribution, and logistics, system for over 30 years. In: Proceeding of the 2011 winter simulation conference. Jain S., Creasey R.R., Himmelspach J., White K.P. and Fu M. (Eds.), Salt Lake City, UT 84116 USA 2011, 39-51.

Nel S., Kazil M.S. and Knights P. (2011). Improving truck-shovel matching. In: $35^{\text {th }}$ APCOM Symposium. Baafi E.Y., Kininmonth R.J. and Porter I. (Eds.).
Wollongong NSW, published by The Australian Institute of Mining and Metallurgy, Carlton Victoria, 381-392.

Newman A.M. and Kuchta M. (2007). Using aggregation to optimize long-term production planning at an underground mine. European Journal of Operational Research, 176(2): 1205-1218. https://doi.org/10.1016/j.ejor.2005.09.008

Raj M.G., Vardhan H. and Rao Y.V. (2009). Production optimization using simulation models in mines: a critical review. International Journal of Operational Research, 6 6(3): 330-359. https://doi.org/10.1504/IJOR.2009.026937

Salama A. (2014). Haulage systems optimization for underground mines: A discrete event simulation and mixed integer programming approach. $\mathrm{PhD}$ thesis, Lulea University of Technology.

Salama A., Nehring M. and Greberg J. (2015). Evaluation of the impact of commodity price change on mine plan of underground mining. International Journal of Mining Science and Technology, 25(3): 375-382. https://doi.org/10.1016/j.ijmst.2015.03.008

Sturgul J.R. (1999). Discrete mine system simulation in the United States. International Journal of Surface Mining, Reclamation and Environment, $\quad 13(2)$ : 37-41. https://doi.org/10.1080/09208119908944207

Topal E. and Ramazan S. (2012). Mining truck scheduling with stochastic maintenance cost. Journal of Coal Science Engineering (China), 18(3): 313-319. https://doi.org/10.1007/s12404-012-0316-4

Yuriy G. and Vayenas N. (2008). Discreteevent simulation of mine equipment systems combined with a reliability assessment model based on genetic algorithms. International Journal of Surface Mining, Reclamation and Environment, 22(1): 0-83. https://doi.org/10.1080/17480930701589674 